Portland State University

PDXScholar

6-16-2021

\title{
Do Secondary Cyclones Increase the Category Scale of Atmospheric Rivers?
}

\author{
Edgar Sanchez Fausto \\ Portland State University
}

Follow this and additional works at: https://pdxscholar.library.pdx.edu/honorstheses

Part of the Atmospheric Sciences Commons, and the Environmental Engineering Commons Let us know how access to this document benefits you.

\section{Recommended Citation}

Sanchez Fausto, Edgar, "Do Secondary Cyclones Increase the Category Scale of Atmospheric Rivers?" (2021). University Honors Theses. Paper 1046.

https://doi.org/10.15760/honors.1072

This Thesis is brought to you for free and open access. It has been accepted for inclusion in University Honors Theses by an authorized administrator of PDXScholar. Please contact us if we can make this document more accessible: pdxscholar@pdx.edu. 
Do secondary cyclones increase the category scale of atmospheric rivers?

\author{
By \\ Edgar Sanchez Fausto
}

An undergraduate honors thesis submitted in partial fulfillment of the requirements for the degree of
Bachelor of Science
in
University Honors
and
Environmental Engineering

Thesis Adviser

Dr. Andrew Martin (Geography)

Portland State University

2021 


\title{
Do secondary cyclones increase the category scale of atmospheric rivers?
}

By Edgar Sanchez Fausto (Environmental Engineering), advised by Dr. Andrew Martin (Geography)

\begin{abstract}
:
Atmospheric rivers (ARs) play a crucial role in delivering precipitation worldwide. This makes them an important phenomenon for water resource specialists to study. One such interest is to understand what mechanisms make ARs produce significant rainfall and associated hazards such as flooding. One possible mechanism is that AR duration or intensity may increase when it interacts with a secondary cyclone, either of which can increase the AR category scale. The purpose of this study is to determine whether AR and secondary cyclone interactions increase the category scale ARs. Out of 52 AR events analyzed, 32 events contained at least one AR and secondary cyclone interaction. Of those 32 events, 25 events had persistent interactions. By conducting a paired t-test to compare the average AR scale at each monitoring station between events with and without persistent interactions, we found that secondary cyclones interactions did cause an increase in AR category scale. Moreover, we also found that events with secondary cyclone interactions produced more impacts measurable by the AR scale on the US West Coast.
\end{abstract}

\section{Introduction/Background:}

Atmospheric rivers are long, narrow corridors of anomalously high water vapor transport in the atmosphere. While they only cover $10 \%$ of the midlatitudes, they make up more than $90 \%$ of the total poleward water vapor transport (Zhu and Newell, 1998). ARs can occur anywhere in the world but tend to appear in the mid latitudes (Guan and Waliser, 2015). In the United States, ARs frequently make landfalls on the west coast (Guan and Waliser, 2015). Moreover, extreme precipitation events associated with ARs can be linked with damaging flood events. On the US west coast, ARs tend to produce twice as much rain as all storms from each winter season (Neiman et al.., 2008). For example, one flooding event caused by an AR occurred in southern California between January 7-11 in 2005. In this event, approximately 10 - 20 inches of rain was received in Los Angeles alone (Barber, 2017). This AR also caused 10 deaths and $\$ 200-\$ 300$ million in damages (Barber, 2017).

Like hurricanes, a scale has been created to categorize ARs (Ralph et al., 2019). The scale, shown in Figure 1 below, varies between 1 and 5 in increments of 1. A category scale $1 \mathrm{AR}$ is not harmless and provides necessary precipitation; on the other hand, a category scale $5 \mathrm{AR}$ is hazardous and can cause disastrous events like floods. Moreover, 
the category scale of an AR is keyed to a specific location. To determine the category scale of an AR, two pieces of information are needed: the maximum IVT magnitude and duration of the AR over the specific location. These two criteria are used to determine what the category scale of an AR is according to Figure 1.
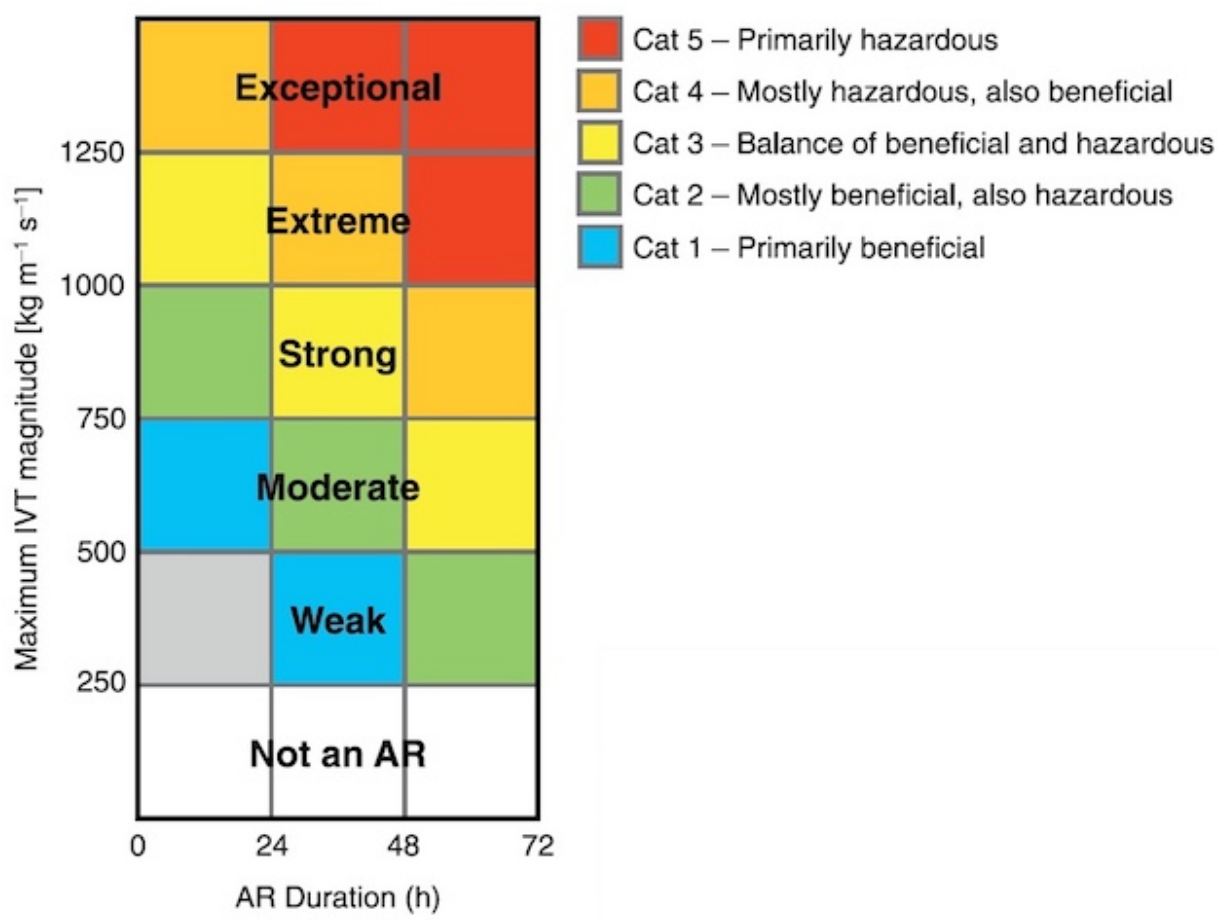

Figure 1: The AR category scale. ( Ralph et al., 2019).

Cyclones are processes which also deliver significant amounts of precipitation. Cyclones, by definition, are large scale air masses that rotate around a strong center of low atmospheric pressure. Extratropical cyclones are cyclones which occur in mid and high latitudes. The manner in which they form, and grow is called cyclogenesis. One understood cyclogenesis is when an upper-level low pressure system moves over a front. A front is a zone where the gradient between a cold air mass and a warm air mass is the largest. A front can also be thought of as the moving boundary between a cold air mass and a warm air mass. This low pressure system causes a kink to form on the front, transforming it into a wave. As the wave strengthens, there is a counter-clockwise movement of air that occurs in the northern hemisphere. After sufficient strengthening, air begins to rotate in a complete circle around the center of low pressure, and a cyclone has formed. Due to global temperature gradients, the cold front moves towards the equator and the warm front moves towards the pole. The poleward-hailing cold front wraps around the wave faster than the equatorward-hailing warm front. Eventually the cold front catches up with the warm front, forming an occlusion. As the occlusion grows, 
the warm front eventually gets cut off, dissipating the cyclone. Extratropical cyclones bring in much of the precipitation in the northern hemisphere. In some mid latitude locations, between $85 \%$ and $90 \%$ of the annual precipitation comes from extratropical cyclones (Hawcroft et al., 2012). Extratropical cyclones can also spawn other cyclones called secondary extratropical cyclones, or simply secondary cyclones. Secondary cyclones are more difficult to predict than primary cyclones, are not as understood as primary cyclones, and can cause hazardous weather events like floods.

The U.S. West Coast is the region of interest in this study. Corringham et al. (2019) found that the AR category scale approximately predicted the logarithm of flood damages reported to the National Flood Insurance Program along the U.S. West Coast, with scale $1 \mathrm{ARs}$ incurring little damage, and scale 5 ARs incurring $10^{5}$ times more damage on average. Albano et. al (2020) found that coastal and maritime mountain ranges are at greater risk for hazardous precipitation events from ARs. By using data from MERRA-2 and employing quantile regression, they were able to quantify the spatial and temporal variability of AR precipitation and the subsequent impacts on land over the western U.S. They found that, between 1980 and 2015, at least 500 AR events occurred on the Oregon coast alone with an average duration of 3 days. Moreover, in Oregon, increasing meridional winds increase the precipitation that comes from ARs. The soils in Oregon tended to have little effect on the runoff variability as they're usually close to saturation, meaning ARs more consistently lead to high streamflow and potentially flooding.

There is very little research on the interactions between secondary cyclones and ARs. A few studies have demonstrated that secondary cyclones can form near ARs and that they can modify AR characteristics such as precipitation (Ralph et al.., 2010; Neiman et al.., 2016; Martin et al.., 2019). However, it's unclear whether secondary cyclones interact frequently with ARs. Moreover, it's unclear what the impacts of secondary cyclones are on AR properties. This study will look at both the frequency with which secondary cyclones and ARs interact over a large number of events and the impact of these interactions on AR category scale.

In a related study, Martin et. al (2019) assessed the relationship between mesoscale frontal waves and the hydrometeorological impact of an AR over northern California. They observed a frontal wave which eventually developed into a secondary extratropical cyclone. With a forecast lead time of 36 hours or less for secondary extratropical cyclones, these events make it difficult to predict the precipitation that will come from an AR. They found that the secondary cyclone produced a shallow warm front, which caused a hiatus in the expected rainfall of the AR on land. After this warm front had transited, precipitation from the AR came back. It was this hiatus which wasn't caught by forecasts and led to an overprediction of the impending rains. 
Given that ARs are a major source of precipitation globally, and given that they occur frequently in the same geographical areas as secondary cyclones, it's worthwhile investigating what their relationship is in terms of landfalling precipitation. One parameter that can demonstrate an impact on landfalling precipitation when ARs and secondary cyclones interact is the AR category scale. If we see that ARs that interact with secondary cyclones have a higher category scale compared to ARs that don't exhibit these interactions, then these interactions do cause an increase in the amount of precipitation and related flood risk. Thus, understanding how secondary cyclones affect the category scale of ARs could help us understand how ARs produce significant precipitation. This will also help water resource managers better understand the hydrologic cycle.

The purpose of this study is to determine whether interaction between ARs and secondary cyclones exists generally over a large number of events and how modification of precipitation may function. This paper will examine the interaction between ARs and secondary cyclones over 52 cases.

\section{Methods:}

\section{1: Identification of $A R$ and secondary cyclone interactions}

A multi-year dataset of AR / secondary cyclone interactions for the US West Coast and the associated Scale for each landfalling AR event was necessary to perform this investigation. This study uses data from the National Aeronautics and Space Administration's (NASA) Modern-Era Retrospective analysis for Research and Application (MERRA-2) database to measure atmospheric conditions related to ARs and Secondary Cyclones. Only landfalling ARs with defined AR scale were chosen so that the resulting dataset included only ARs with well-defined impacts. Constructing the dataset proceeded in three parts: Identification of landfalling AR events with known scale, geometric identification of AR objects contributing to landfalling AR Scale events, and geometric identification of secondary cyclones occuring near a landfalling AR "edge-front".

The GNU Image Manipulation Program, or GIMP, was used to carry out all three steps. There are three image sets that are used: mean sea level (SLP) (Figure 2, left), gradient of potential temperature or $\nabla \theta_{\mathrm{e}}$ (Figure 2, center), and detected ARs (Figure 2, right). Each image is given in the following format: (year)-(month)-(day) (time), where the time is in coordinated universal time (UTC). The time resolution is every 6 hours. In addition to these images, two new layers were created in gimp to mark the secondary cyclones and AR edge-fronts. 

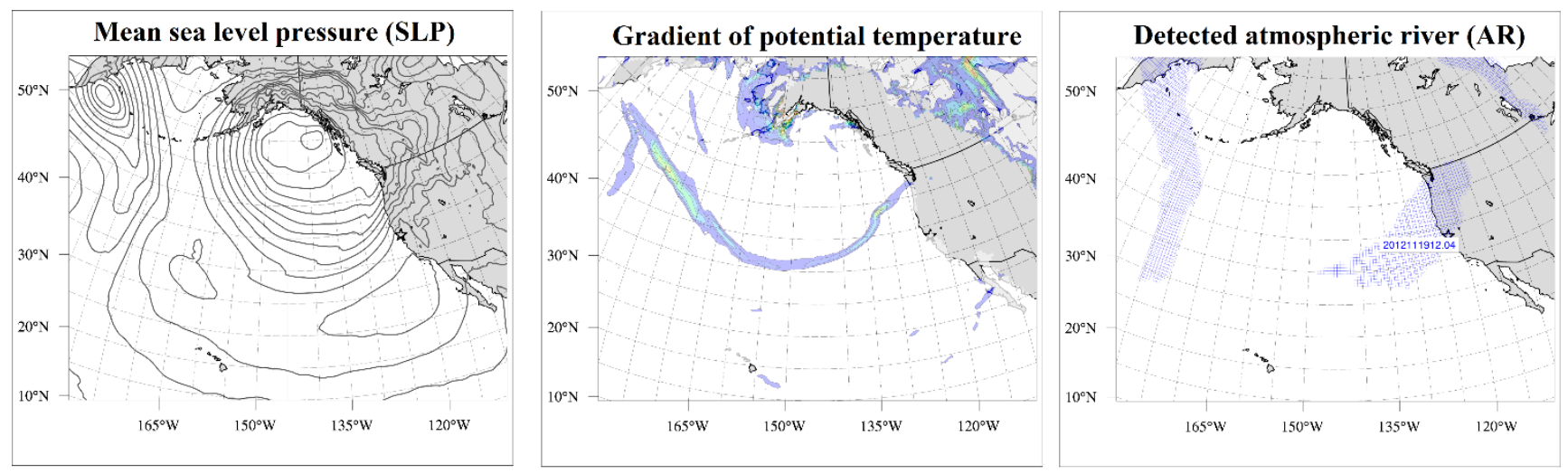

Figure 2. There are three image sets that are used: Left) mean sea level (SLP), Center) $\nabla \theta_{\mathrm{e}}$, and Right) detected ARs from the Guan and Waliser (2015) MERRA-2 based AR Catalog. Each image is valid for a moment in time, given in the following format: (year)-(month)-(day) (time), where the time is in coordinated universal time (UTC). By overlaying these images in a graphical editing software (GiMP), interaction between the $A R$, its edge fronts and secondary cyclones can be inferred.

The first step is to identify landfalling ARs with known scale over selected points on the US west coast between 2010 and 2016. In order to identify an AR, the technique outlined in Guan et al.. (2015) will be used. This technique will be applied to atmospheric data from MERRA-2 atmospheric model (Gelaro et al.., 2017). As shown in Figure 3, the AR is deemed as landfalling wherever the detected AR, represented by the blue gridded areas, makes contact with one of the monitoring stations on the US west coast: $48^{\circ} \mathrm{N}, 46^{\circ} \mathrm{N}, 44^{\circ} \mathrm{N}, 42^{\circ} \mathrm{N}, 40^{\circ} \mathrm{N}, 38^{\circ} \mathrm{N}, 36^{\circ} \mathrm{N}, 34^{\circ} \mathrm{N}$, and $32^{\circ} \mathrm{N}$ latitude. If any part of the detected AR grid overlaps with one of the monitoring stations for more than 12 consecutive hours, the technique of Ralph et al. (2019) is used to determine the AR scale for the monitoring station, including maximum IVT and duration of AR conditions over the station. All AR objects from the Guan et al. detection method that contributed to any contiguous period of AR conditions at any of the 9 US West Coast monitoring stations were retained for potential secondary cyclone interaction analysis (e.g. steps 2 and 3). 


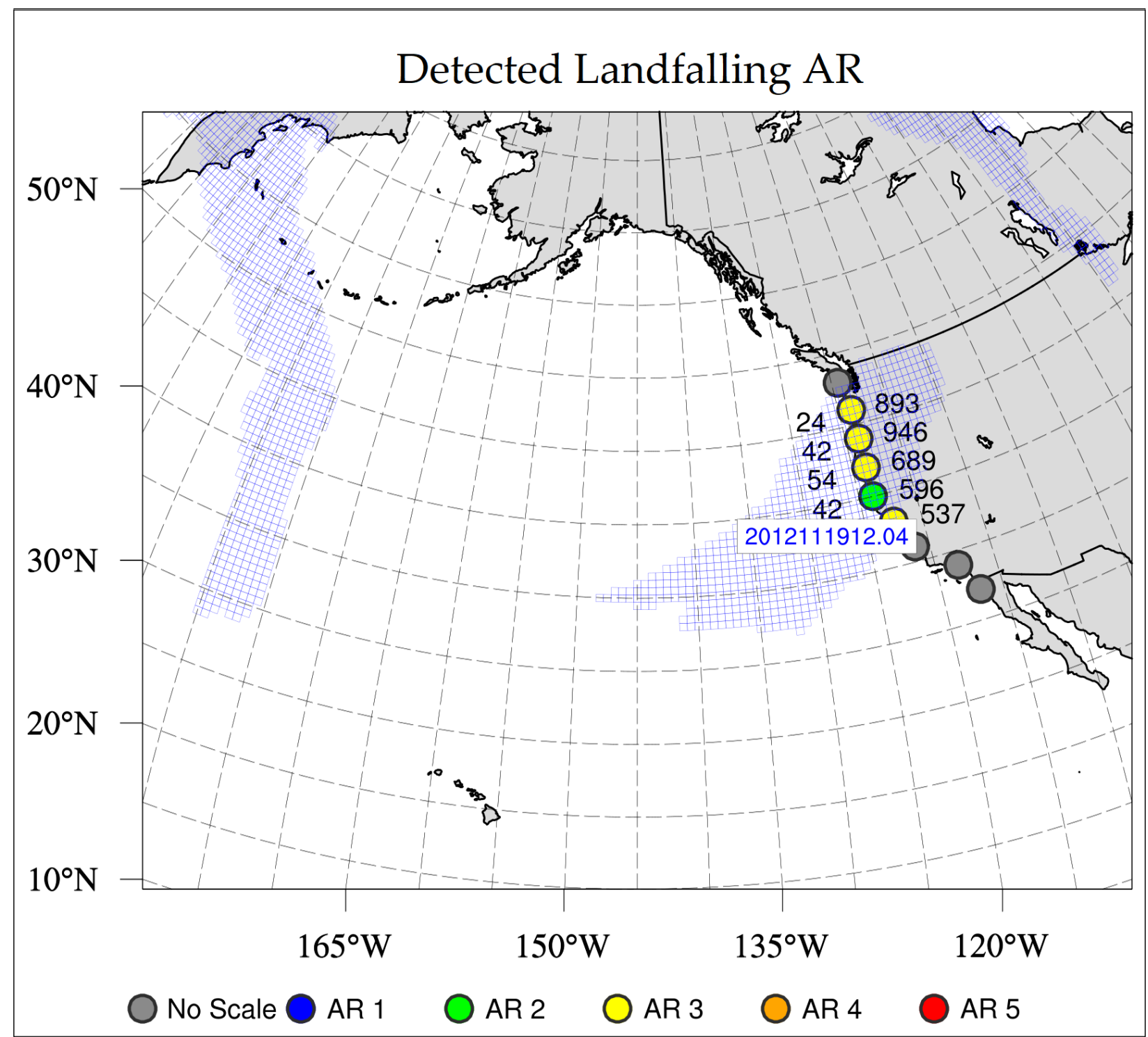

Figure 3. A detected AR on 2012-11-19 12 UTC, shown as the blue grid area, making landfall by touching one of the monitoring stations represented by the circles.

After identifying the landfalling AR, the AR edge-fronts contained within the landfalling AR scale event were geometrically identified in GIMP. The edge-fronts of the AR are the points where $\nabla \theta_{\mathrm{e}}$, shown in Figure 4, is greater than $2 \mathrm{Kelvin} / 100 \mathrm{~km}$ and overlaps with the detected AR. The AR edge-fronts were outlined in red in GIMP, as shown in Figure 5 . 


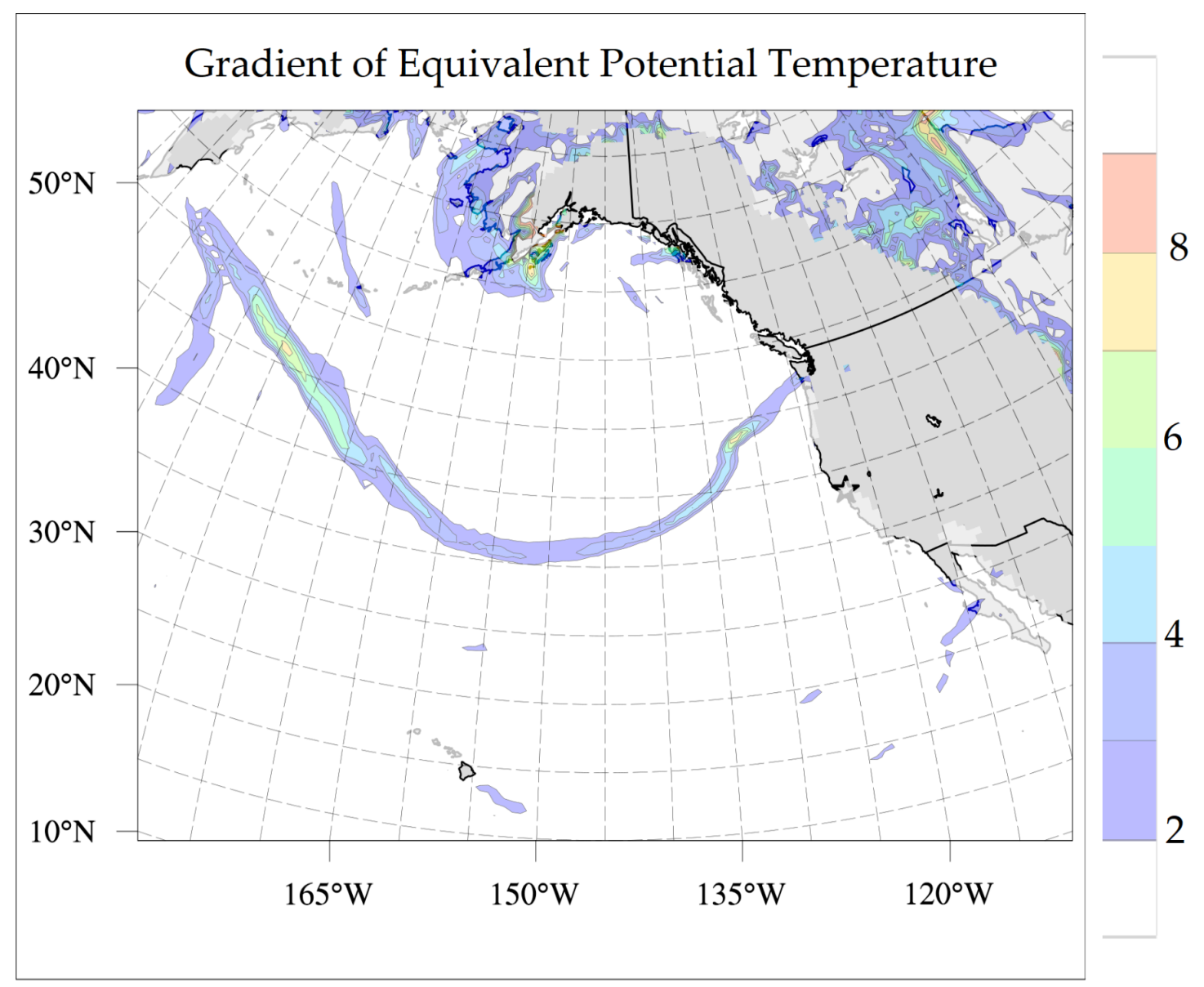

Kelvin/100 km

Figure 4. An image of $\nabla \theta_{\mathrm{e}}$, which is shown by the shaded colored region Kelvin/100 km. 


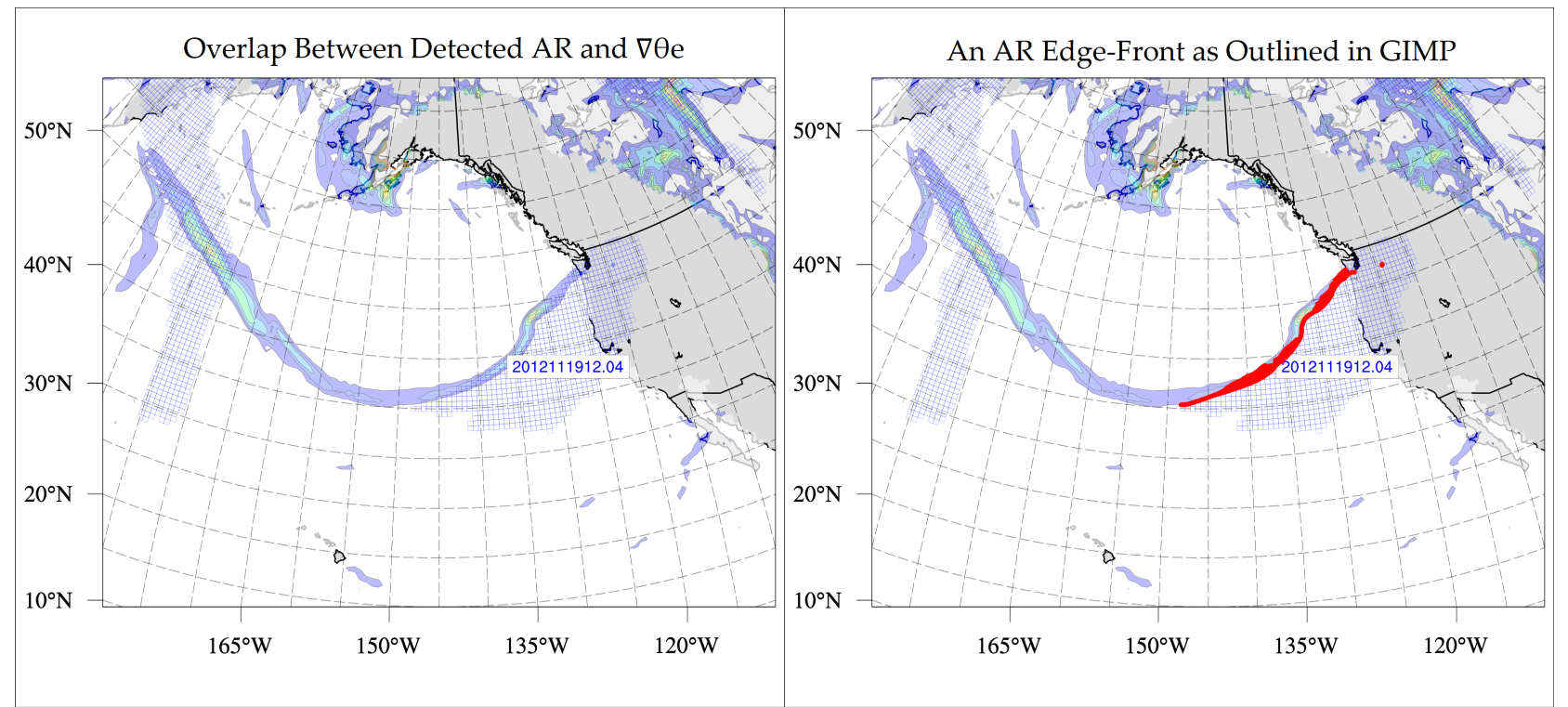

Figure 5. Left) the overlap between a detected AR on 2012-11-19 12 UTC and $\nabla \theta_{\mathrm{e}}$ before marking it in red in GIMP, Right) the AR edge-front marked in red.

Having outlined the AR edge fronts for each time step, the next step will be to geometrically identify secondary cyclones near the AR edge-fronts. This will be done by using a cyclone detection algorithm from Wernli and Schierz (2006). This is defined as looking for the outermost closed isobar that wasn't present in the previous timestep in a low pressure system. For example, Figure 6 below shows the SLP map on 2012-11-19 06 UTC. We see that in the next time step at 12 UTC, shown in Figure 7, a new cyclone has appeared near $45 \mathrm{~N}$ and $-130 \mathrm{~W}$. This would be classified as a secondary cyclone and outlined in black in GIMP in a different layer (Figure 8). Any closed isobars that were smaller than 2 detected AR grid-boxes or one latitude-longitude grid dash on a side were disregarded. Each cyclone present was checked for distance traveled, as cyclones don't usually move more than $10^{\circ}$ latitude or longitude between each time step. If a cyclone met the criteria outlined in Wernli and Schierz (2006), as well as the size requirements, then it would be marked as a secondary cyclone. This was done for all time steps in which the AR was landfalling after the initial time step. 


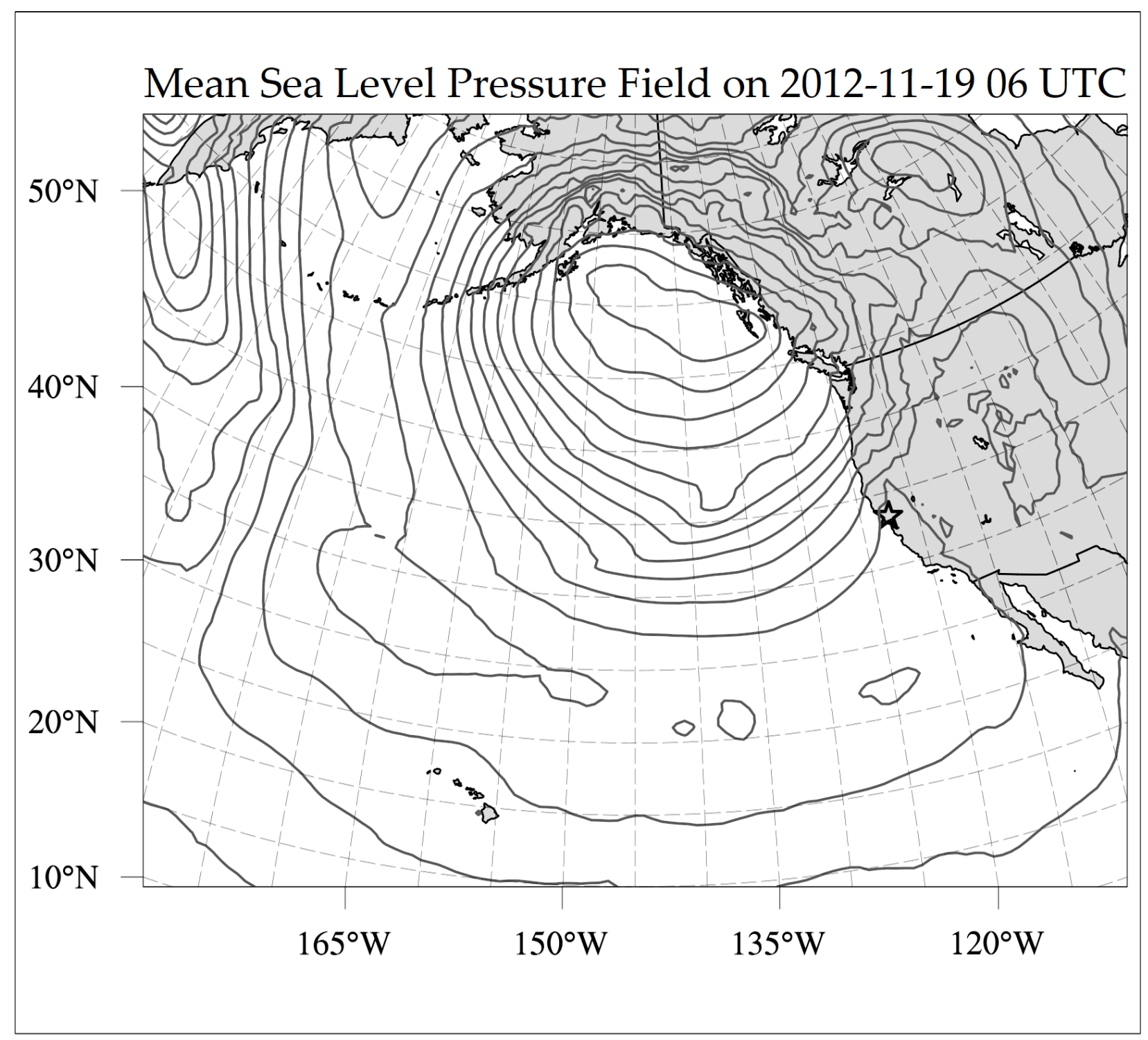

Figure 6. The SLP map on 2012-11-19 06 UTC. 


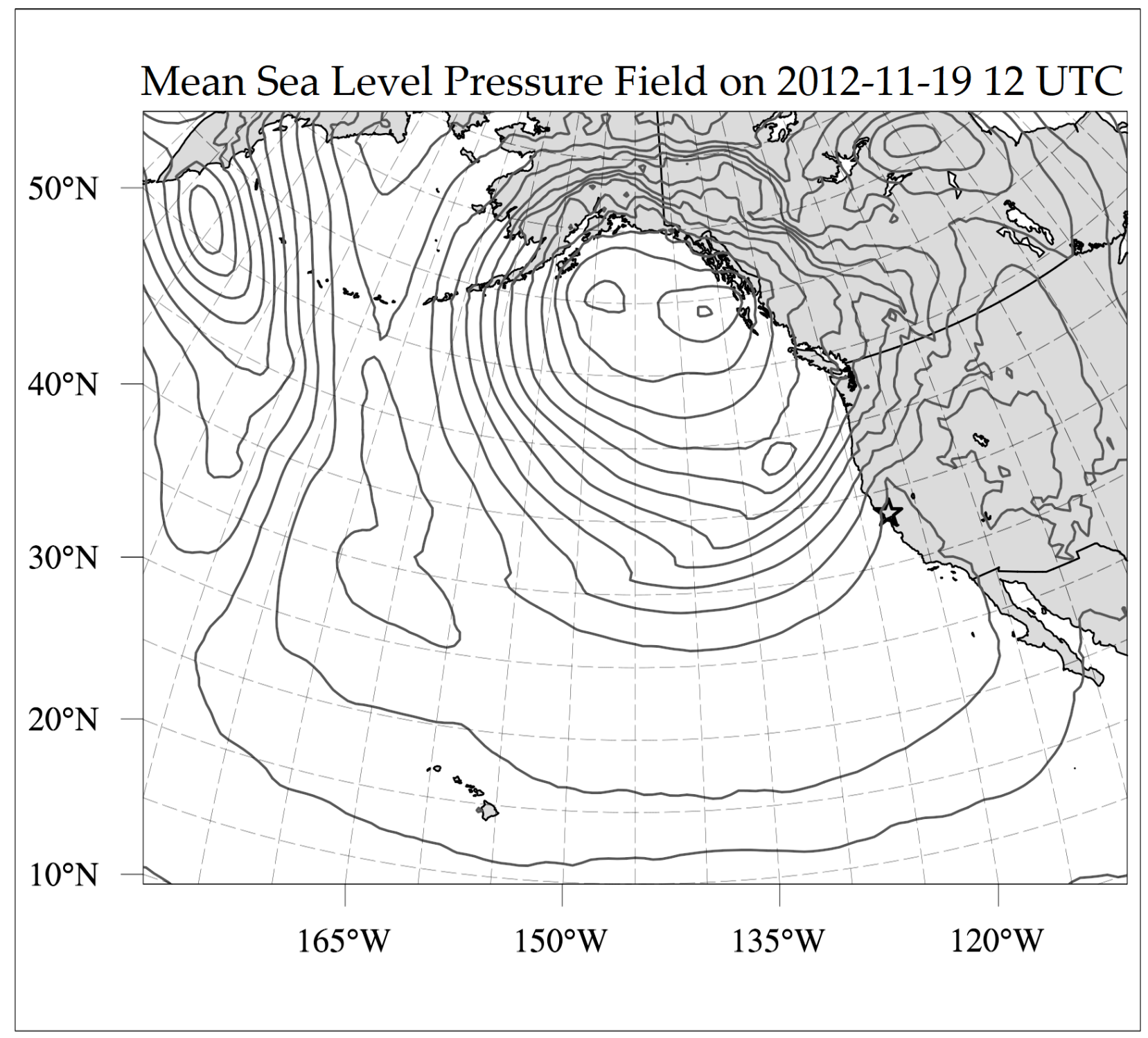

Figure 6. The SLP map on 2012-11-19 12 UTC, where a new cyclone has appeared near $45 \mathrm{~N}$ and $-130 \mathrm{~W}$. 


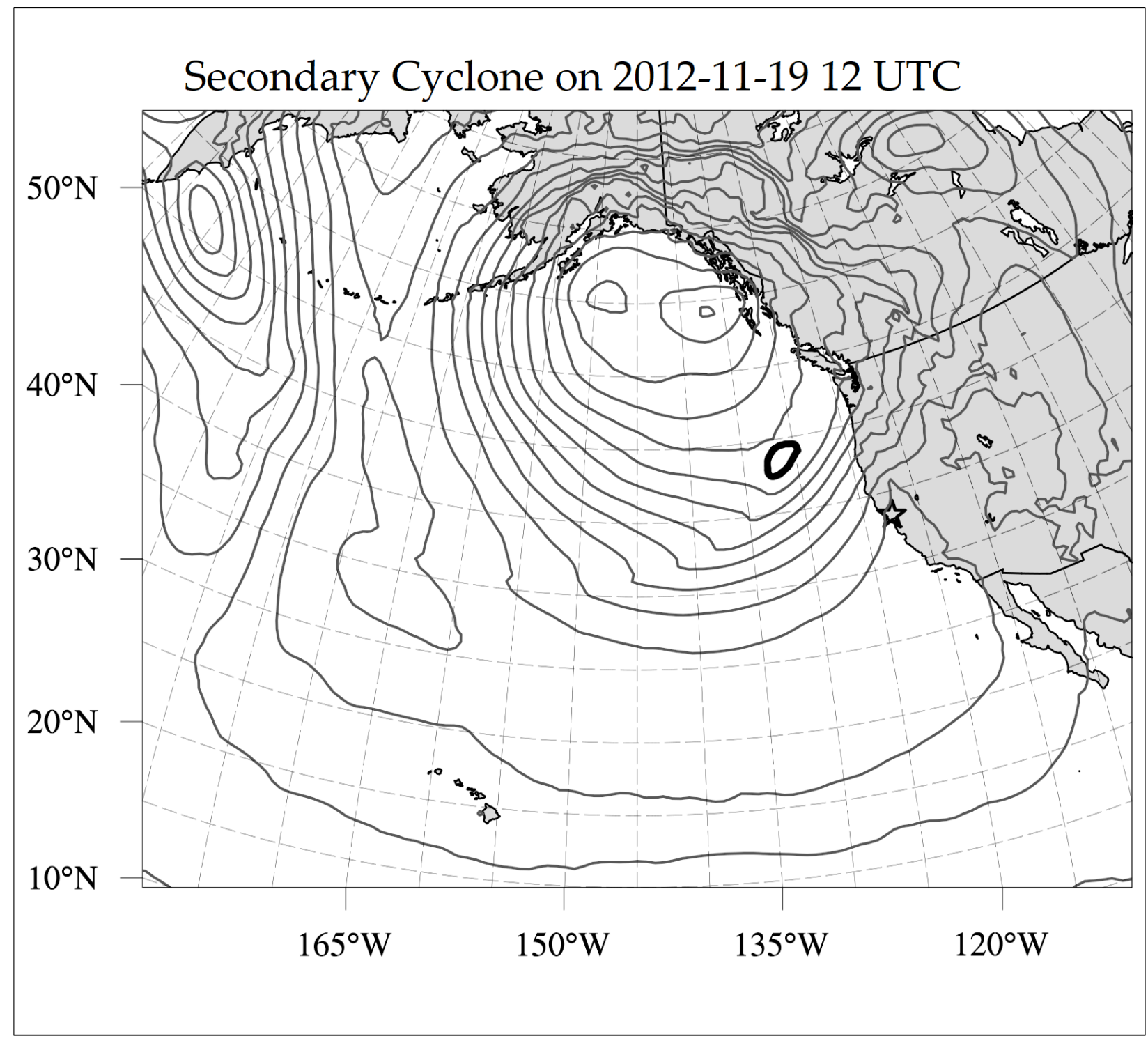

Figure 8. The SLP map on 2012-11-19 12 UTC, where a secondary cyclone near $45 \mathrm{~N}$ and $-130 \mathrm{~W}$ is outlined in black in GIMP in a different layer.

An interaction between the AR and secondary cyclone will be defined as all points where the AR edge-fronts overlap with the secondary cyclone. The secondary cyclone and AR edge-front must be within 1 detected AR grid-box to declare an interaction. This interaction will then be recorded as the center coordinates for the secondary cyclone together with the timestamp of the AR. A unique identification code for the AR and cyclone location will be recorded in a spreadsheet. 


\section{2: Analysis of AR category scale for events with and without secondary cyclone interactions}

In addition to three datasets used to identify secondary cyclone and AR interactions, a dataset to identify the AR category scales associated with each event will be used. This dataset comprises 9 monitoring stations on the US west coast, each separated by two degrees of latitude: $48^{\circ} \mathrm{N}, 46^{\circ} \mathrm{N}, 44^{\circ} \mathrm{N}, 42^{\circ} \mathrm{N}, 40^{\circ} \mathrm{N}, 38^{\circ} \mathrm{N}, 36^{\circ} \mathrm{N}, 34^{\circ} \mathrm{N}$, and $32^{\circ} \mathrm{N}$ (Figure 9). In addition to showing the scale of the AR, each station also records the maximum duration and IVT magnitude of the AR over that point (Figure 10). The maximum duration of the AR is given by the number to the left of the station, while the number on the right is the maximum IVT value.

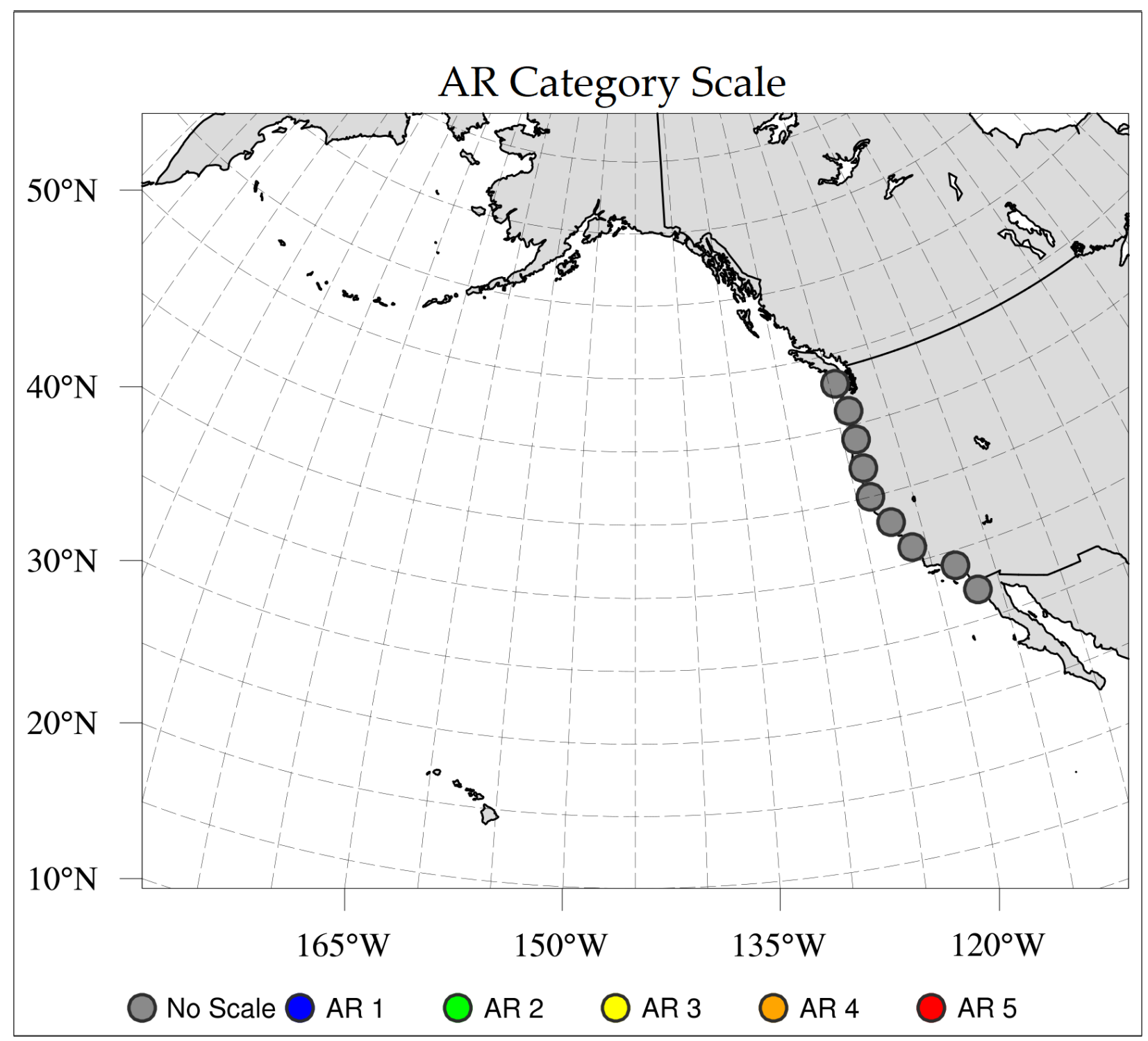


Figure 9. The 9 monitoring stations on the US west coast, each separated by two degrees of latitude: $48^{\circ} \mathrm{N}, 46^{\circ} \mathrm{N}, 44^{\circ} \mathrm{N}, 42^{\circ} \mathrm{N}, 40^{\circ} \mathrm{N}, 38^{\circ} \mathrm{N}, 36^{\circ} \mathrm{N}, 34^{\circ} \mathrm{N}$, and $32^{\circ} \mathrm{N}$.

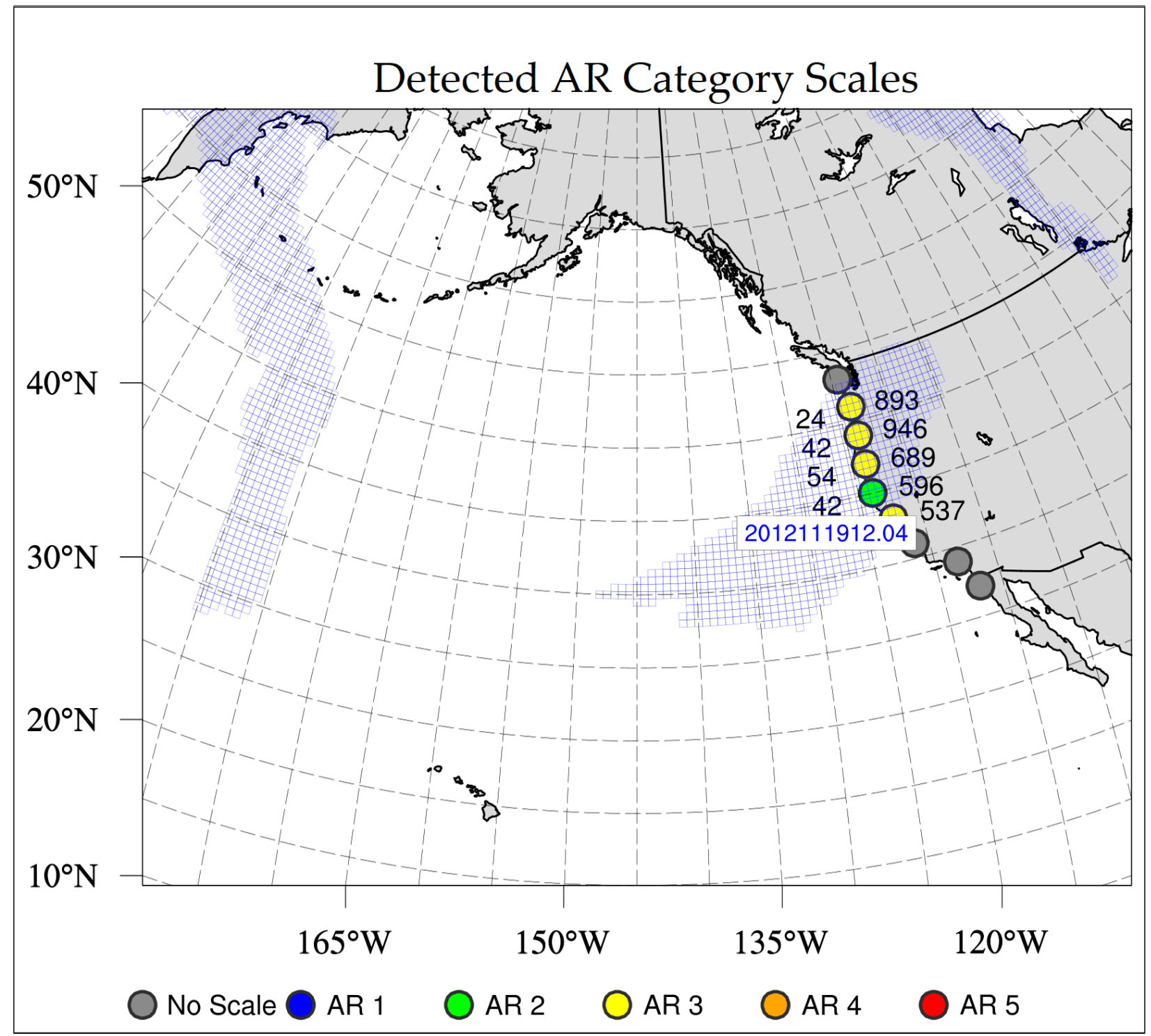

Figure 10. A sample of how each station also records the maximum duration (number to left of station) and IVT magnitude (number to right of station) for a landfalling AR on 2012-11-19 12 UTC.

The detected AR category scale, maximum AR duration, and maximum AR IVT at any of these monitoring stations was recorded in a spreadsheet. These data were recorded only for the earliest time step at which the AR scale was detected. This information was further separated into two categories: AR events with secondary cyclone interactions, and AR events without secondary cyclone interactions. 


\section{3: Statistical analysis of AR categories scales between events with and without secondary cyclone interactions}

After tabulating the frequency of each AR category scale over the 9 monitoring stations, a paired t-test will be performed to compare the AR scales of AR events with and without interactions. In order to tabulate the data into a form usable for the paired t-test, the weighted average AR category scale will be computed at each monitoring station. Any monitoring station which had only one total recorded AR category scale was discarded, as this does not give enough weight to associate an average AR scale to that station. This only occurred for stations 34 and 32 within the group of AR events without interactions. The null hypothesis would be that any difference in AR category scales between events with and without secondary cyclone interactions are due to outside variables. In order to reject the null hypothesis, a p-value of less than 0.05 must be obtained.

In addition to comparing the average AR category scales, a t-test will be used to compare the frequency of detected AR category scales at each station as well. In this instance, the null hypothesis is that any difference in the frequency of detected AR category scales are due to outside variables and not secondary cyclone interactions.

Lastly, as a measure of quality control, we used events with a secondary cyclone interaction that spanned at least two valid time steps. We define this to be "persistent interactions", wherein the AR event has had a secondary cyclone interaction over more than one valid time step. This improves the quality of our analysis by eliminating those events where only one interaction occurred, which likely wouldn't affect the AR category scale. Since the time resolution of MERRA-2 is every 6 hours, a secondary cyclone which interacted with an AR event once over the duration of the AR cannot confidently be said to have influenced the AR for more than 6 hours. This duration is considered insufficient to impact the category scale of the AR, because the minimum duration required to produce an AR scale 1 is 12 hours. Those AR events which had more than one interaction over non-continuous time steps, such as at o UTC and 12 UTC, are included. 


\section{3: Results}

There were a total of 52 AR events analyzed. From the 52 AR events analyzed, 32 cases had at least one AR and secondary cyclone interactions. Of those 32 events with at least one interaction, 25 events had persistent interactions. The longest consecutive interaction lasted 48 hours and the least lasted 6 hours.

The frequency of AR category scales recorded at each monitoring station for AR events with and without interactions are given in Figure 10 and Figure 11, respectively. Note that Figure 10 omits those events with only one interaction. Overall, AR events with interactions collectively had 132 detected AR category scales. This is in contrast to AR events without interactions, which had 84 total detected AR scales. The highest category scale recorded was 5 and it was associated with AR events that had a persistent interaction. Note that AR events without interactions did not have any ARs with category scales 4 and 5 .

Frequency of AR Category Scales With Interactions

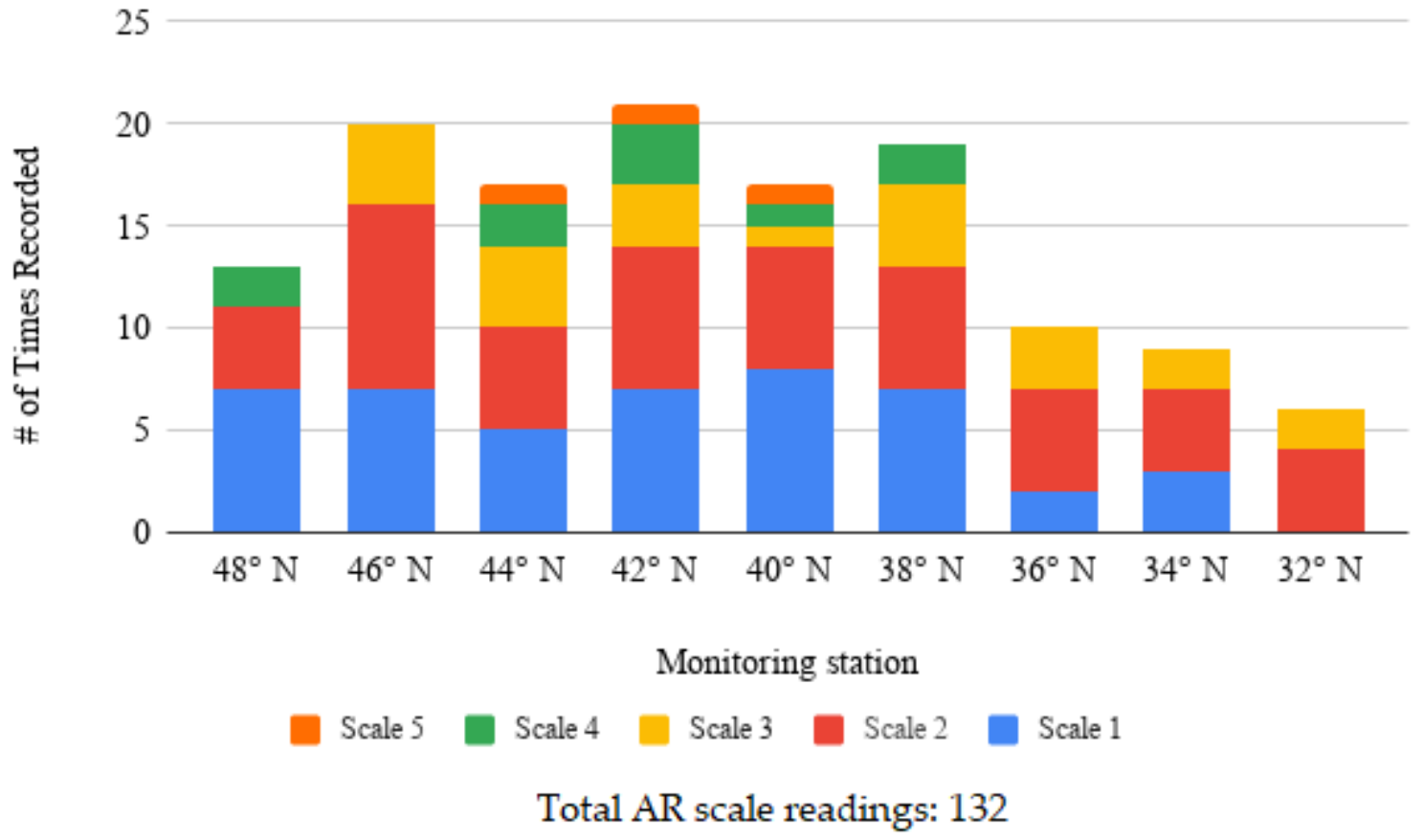

Figure 11. The total number of the different AR category scales recorded at each station for cases with secondary cyclone and AR interactions. 


\section{Frequency of AR Category Scales Without Interactions}

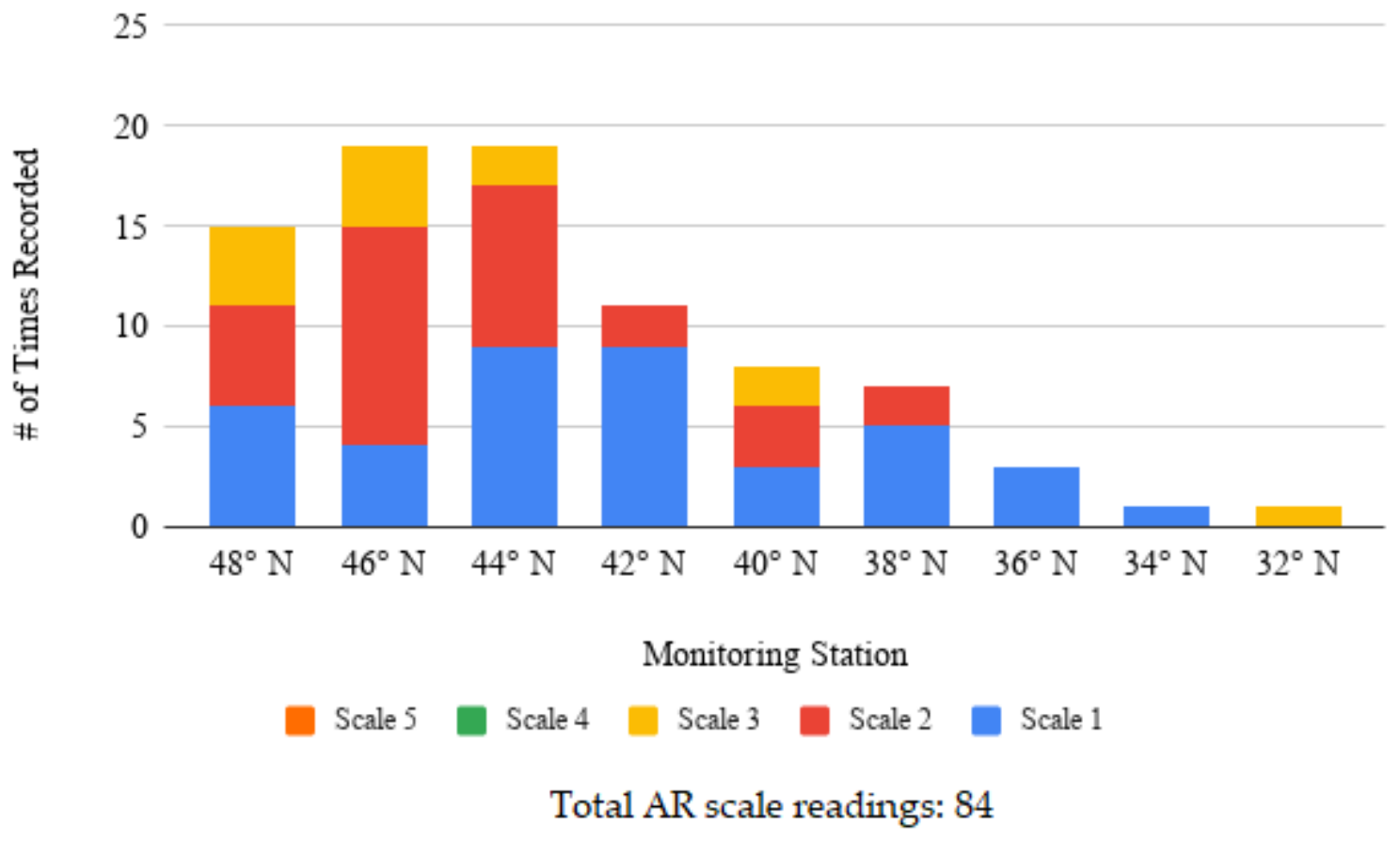

Figure 12. The total number of the different AR category scales recorded at each station for cases without secondary cyclone and AR interactions.

The weighted average AR category scale at each station for events with and without interactions are given in Table 1 and Table 2, respectively. In addition, these tables show the number of detected AR scales at each station. We can see that the average AR scale at stations where events had interactions are slightly higher than those without interactions. Moreover, stations which had events with interactions also had more recorded AR scales compared to events without interactions. Running a paired t-test gave p-values of less than 0.05 when comparing average AR category scale and detected AR category scale frequency (Table 3 ). 
Table 1: The average scale and number of recorded AR category scales at each monitoring station with interactions.

\begin{tabular}{|l|r|r|}
\hline $\begin{array}{l}\text { Monitoring } \\
\text { Station }\end{array}$ & $\begin{array}{l}\text { Average } \\
\text { Scale }\end{array}$ & $\begin{array}{l}\text { Number of } \\
\text { Readings }\end{array}$ \\
\hline $32^{\circ} \mathrm{N}$ & 2.3 & 6 \\
\hline $34^{\circ} \mathrm{N}$ & 1.9 & 9 \\
\hline $36^{\circ} \mathrm{N}$ & 2.1 & 10 \\
\hline $38^{\circ} \mathrm{N}$ & 2.1 & 19 \\
\hline $40^{\circ} \mathrm{N}$ & 1.9 & 17 \\
\hline $42^{\circ} \mathrm{N}$ & 2.2 & 21 \\
\hline $44^{\circ} \mathrm{N}$ & 2.4 & 17 \\
\hline $46^{\circ} \mathrm{N}$ & 1.9 & 20 \\
\hline $48^{\circ} \mathrm{N}$ & 1.8 & 13 \\
\hline
\end{tabular}

Table 2: The average scale and number of recorded AR category scales at each monitoring station without interactions

\begin{tabular}{|l|r|r|}
\hline $\begin{array}{l}\text { Monitoring } \\
\text { Station }\end{array}$ & $\begin{array}{l}\text { Average } \\
\text { Scale }\end{array}$ & $\begin{array}{l}\text { Number of } \\
\text { Readings }\end{array}$ \\
\hline $32^{\circ} \mathrm{N}$ & 0 & 1 \\
\hline $34^{\circ} \mathrm{N}$ & 0 & 1 \\
\hline $36^{\circ} \mathrm{N}$ & 1 & 3 \\
\hline $38^{\circ} \mathrm{N}$ & 1.3 & 7 \\
\hline $40^{\circ} \mathrm{N}$ & 1.9 & 8 \\
\hline $42^{\circ} \mathrm{N}$ & 1.2 & 11 \\
\hline $44^{\circ} \mathrm{N}$ & 1.6 & 19 \\
\hline $46^{\circ} \mathrm{N}$ & 2.0 & 19 \\
\hline $48^{\circ} \mathrm{N}$ & 1.9 & 15 \\
\hline
\end{tabular}


Table 3: The p-values obtained from the paired t-test comparing the average AR scale and number of AR scale readings.

\begin{tabular}{|l|r|}
\hline & P-Value \\
\hline Average AR Scale & 0.01897 \\
\hline Number of Readings & $1.51 \mathrm{E}-02$ \\
\hline
\end{tabular}

\section{4: Discussion}

To best capture the observations obtained from these 52 cases, two exemplary examples will be analyzed in depth. The first case falls into the single-interaction category, and the second will look at a case with multiple interactions. The first case will discuss the AR observed on 2012-11-16 at 06 UTC. This AR will hence be referred to as AR 2012111606. The second case will discuss the AR observed on 2014-02-27 at oo UTC, which will be referred to as AR 2014022700.

The time steps before, during, and after the interaction for AR 2012111606 are shown in Figure 2. The time step before the interaction, which is 2012-11-19 at 06 UTC, shows a clear wave occurring in the pressure field near $40 \mathrm{~N}$ and $140 \mathrm{~W}$. Waves like these in the pressure field are a good indicator that secondary cyclogenesis may be imminent. Moreover, seeing as the AR is touching the pressure field along this point, it's very likely that a secondary cyclone and AR interaction is about to occur. Moving onto the next time step at $12 \mathrm{UTC}$, we see that a new closed isobar has appeared at $132 \mathrm{~W}$ and $43 \mathrm{~N}$. This cyclone is indeed a secondary cyclone. We see that the wave occurring in the pressure field 6 hours before is likely to have influenced the formation of this secondary cyclone. A similar phenomenon occurred in the study conducted by Martin et al. (2019).

The secondary cyclone in this case does indeed overlap with an edge front on AR 2012111606 at 12 UTC (Figure 13). This means that there is an interaction between this AR and the secondary cyclone. At this point, the next step in analyzing this interaction is to see if it persists in future time steps. There were no clear patterns or indicators for persisting secondary cyclones in these cases, so each secondary cyclone must be tracked by observation. In this instance, the secondary cyclone had dissipated by the next time step at 18 UTC. This can be seen in Figure 2 as there is no closed isobar where the cyclone had been. However, there are more waves in the pressure field near $45 \mathrm{~N}$ and $130 \mathrm{~W}$ at $18 \mathrm{UTC}$. These waves, however, did not create more secondary cyclones. Thus, this is a case where only one interaction had occurred over the duration of the AR.

This case demonstrates, firstly, the variability of secondary cyclones. While the waves occurring at 06 UTC were followed by a secondary cyclone, similar waves at 18 UTC did 
not yield more secondary cyclones. Thus, while waves in the pressure field are a good indicator for secondary cyclone formation, they don't always induce secondary cyclones. Moreover, the short lifespan of the secondary cyclone shows that they can be hard to forecast. The study by Martin et al. (2019) found that a lead time of 36 hours proved to be the most accurate in predicting their event.

However, given that only 8 out of the 32 events with interactions had only one secondary cyclone and AR interaction, it may be better to develop forecasts that can predict long lasting interactions. This is because it's more likely that a long lasting interaction will have a greater impact on AR features compared to a single isolated interaction. For instance, the Martin et al. (2019) study found that a shallow warm front created a hiatus of AR precipitation. While this front did not strengthen the precipitation that followed, it did make it difficult to forecast. Moreover, that secondary cyclone did last for more than 6 hours, making it have at least two interactions. Thus, determining the impacts of longer interactions on AR features is worthwhile.

The next case, AR 2014022700, had an interaction that lasted for 24 hours (Figure 14). In the time step before the first interaction, which was 2014-02-27 at 12UTC, we could see that there are waves in the pressure field near $135 \mathrm{~W}$ and $30 \mathrm{~N}$. These waves were then followed by a secondary cyclone located at $134 \mathrm{~W}$ and $33 \mathrm{~N}$ in the next time step (Figure 3, 2014-02-27 at 18UTC). This secondary cyclone grew in size in the following time steps and moved very little from its initial location. In the time steps between 2014-02-27 at 18 UTC and 2014-02-28 at 18 UTC, this secondary cyclone had interactions with an edge front on the AR. This means that there were a total of 5 interactions.

Firstly, this event stands out in that the growth of this secondary cyclone seems to be tied with the way the detected AR is pulled northward throughout the interaction. We see that, by the end of the interaction, the detected AR had grown to cover almost half of the U.S. west coast. In the time step before the first interaction, we see that the AR mostly hits Baja California, Mexico, and leads into the US from there. Moreover, the shape and trajectory of the AR at this time step is somewhat linear at this time step. However, as the interaction goes on, the AR begins to be pulled northward and becomes more glob-like in shape. Rather than being pulled from the middle, the detected AR grows from its western tail. As it continues to grow and move, it becomes glob-like in shape. This is shown most prominently in the final time step of the interaction.

Seeing how this secondary cyclone is likely to have affected the size and trajectory of the detected AR, it may be best to modify forecasts in order to predict these longer lasting interactions. In the study by Martin et al. (2019), the secondary cyclone had no observed effect on the strength of the AR. However, it did create a hiatus in precipitation which 
caught forecasts off guard. Seeing as this was only one event, it does not rule out the possibility that other interactions, such as the one presented in this study, could impact AR strength and precipitation magnitudes.

One way a secondary cyclone could influence precipitation is by increasing the duration of the AR and keeping the IVT levels steady. In this manner, the precipitation coming from an AR is more than predicted. Depending on the level of IVT and the amount of time the AR is extended, even a strong but small storm could become hazardous. A study by Neiman et al. (2010) found that a mesoscale frontal wave had this impact on an AR in the U.S. pacific northwest. They found that in northwest Oregon, the heaviest rain produced by an AR occurred during its interaction with the wave. The total amount of rainfall recorded was 7.9 inches. They identified orographic processes as an influence on the enhanced amount of precipitation. Moreover, they found that the wave had kept moisture levels steady in the AR and thus prolonged its rainfall.

The cases analyzed have some similarities to the studies mentioned in the introduction. The first is that these 32 cases demonstrate how quickly secondary cyclones can form. In the study by Martin et al. (2019), the most accurate lead time for forecasting their secondary cyclone was 36 hours. In the study by Neiman et al. (2010), they found that the best forecast lead time was 24 hours. This isn't the best as it doesn't give emergency preparedness groups enough time to plan. Moreover, as shown by AR 2014022700, secondary cyclones could impact more than just AR scale. While the study by Neiman et al. (2010) found that a 3-day lead time accurately predicted major precipitation, it did not account for the mesoscale frontal wave or its impacts. One of those impacts includes the change in the AR position. This could create an even bigger problem for forecasting and emergency preparedness.

These findings are of particular importance to Oregon. Given that the study by Albano et al. (2020) shows that an AR lasts an average of 3 days on the Oregon coast, it is very likely that a significant number of ARs have at least one interaction with a secondary cyclone on one of those days. 

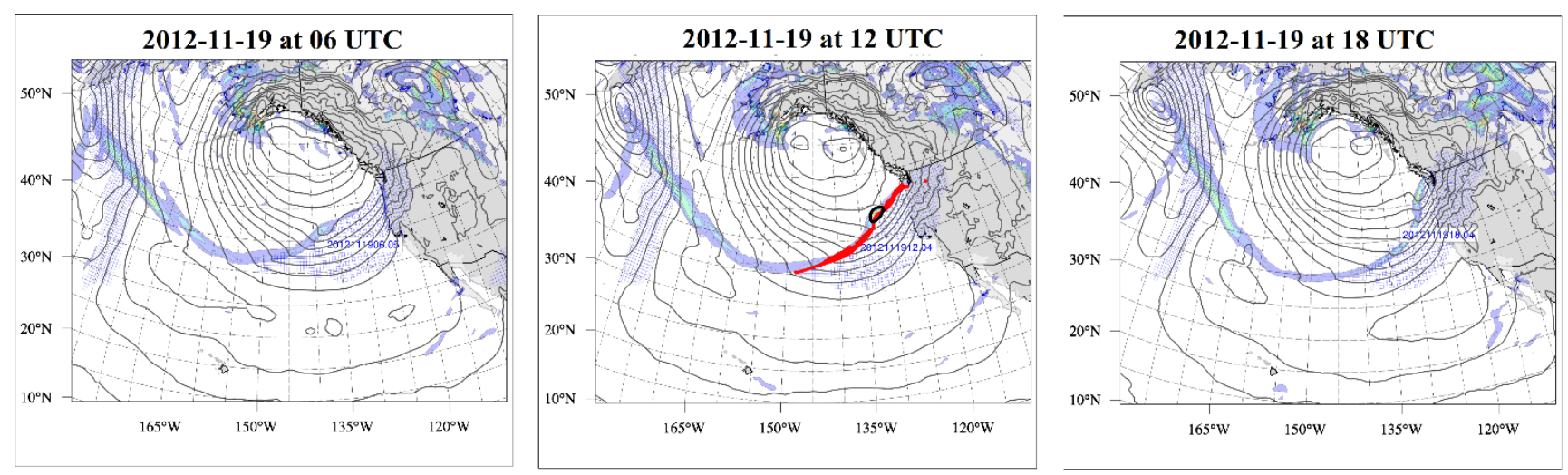

Figure 13. AR 2012111606 before (left), during (center), and after (right) its interaction with a secondary cyclone.
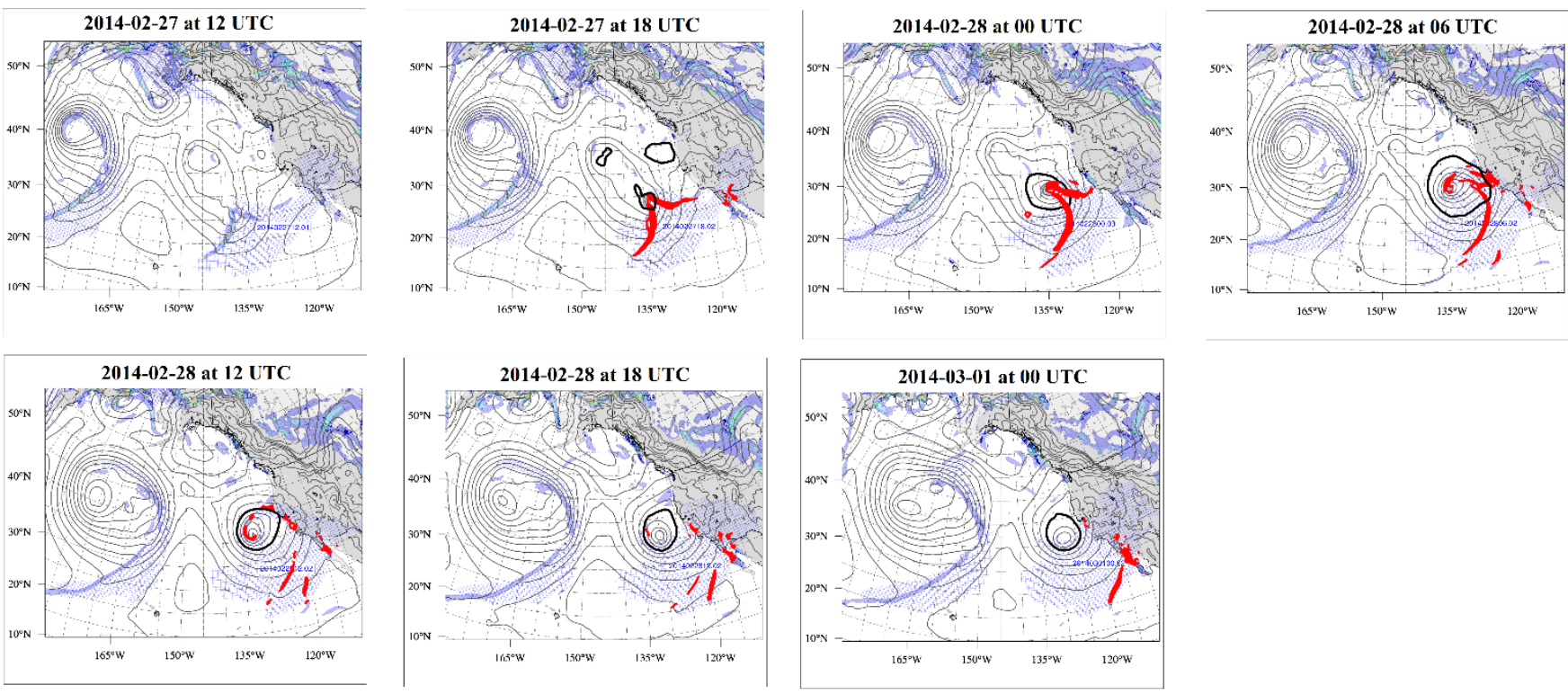

Figure 14. AR 201402270o before (2014-02-27 12 UTC), during (2014-02-27 18 UTC through 2014-02-28 18 UTC), and after its interaction (2014-03-01 oo UTC) with a secondary cyclone.

From Table 1 and Table 2, we can see that AR events with interactions generally had ARs with higher category scales and more ARs with a category scale compared to AR events without interactions. We also see that in Figure 11 the presence of category scale 4 and 5 ARs, whereas there's an absence of these category scales in Figure 12. However, when comparing the weighted average AR category scale at each station between these two groups, we see that there is usually $>1$ difference in the category scale magnitude (Table 1 and Table 2). Yet the difference in the number of detected AR scales between 
these two groups is visually apparent (Table 1 and Table 2). The monitoring stations which had AR events with interactions had detected more AR scales than their counterpart group.

Nevertheless, when comparing both the average AR scale and frequency of detected AR scales at each station between the two groups, the t-test yielded a p-value of less than 0.05 for both (Table 3). This means that we could reject our null hypotheses and attribute these differences to the secondary cyclone and AR interactions. Logically, it makes sense that if secondary cyclone and AR interactions increase the category scale of ARs, then there will be more ARs that will have a detectable AR scale. Thus, these findings pair well together.

By looking at Table 1 , we can see that the average AR scale at each station for events with interactions is generally around 2. On the other hand, we see that the average AR scale for events without interactions is usually between 1 and 2 (Table 2). While this difference may not be great, it does account for the large number of scale 2 ARs shown in Figure 11. We can also see that AR events with interactions also had many more category 2 ARs compared to events without interactions (Figure 11 and Figure 12).

However, determining a specific mechanism by which this increase in AR scale occurs is more complicated. Seeing how AR 2014022700 grew in size during its interaction with a secondary cyclone, this could very well be an influence on the duration of the AR. Also, given the findings by Neiman et al. (2010), secondary cyclones are likely to influence the duration of the AR as they tend to form from waves. By increasing the duration of the AR, we can potentially increase the scale of that AR (Figure 1). Further research could determine this by comparing the maximum IVT and duration of these AR events.

\section{5: Conclusion}

A total of 52 cases with detected ARs were analyzed for interactions with secondary cyclones. A total of 32 cases had at least 1 interaction. Of those 32 cases, 25 had persistent interactions. By conducting a paired t-test to compare the average AR scale at each monitoring station between events with and without interactions, we found that secondary cyclones interactions did cause an increase in AR category scale. Moreover, we also found that events with secondary cyclone interactions detected more ARs with an associated scale. The specific mechanisms by which secondary cyclones increase the scale of an AR may be a next step in investigating these interactions. 


\section{References:}

Akiyama, S., Shige, S., Yamamoto, M. K., \& Iguchi, T. (2019). Heavy ice precipitation band in an oceanic extratropical cyclone observed by GPM/DPR: 1 . A case study. Geophysical Research Letters, 46, 7007- 7014.

https://doi-org.proxy.lib.pdx.edu/10.1029/2019GL082896

ALBANO, C. M., DETTINGER, M. D., \& HARPOLD, A. A. (2020). Patterns and Drivers of Atmospheric River Precipitation and Hydrologic Impacts across the Western United States. Journal of Hydrometeorology, 21(1), 143-159. https://doi-org.proxy.lib.pdx.edu/10.1175/JHM-D-19-0119.1

Barber, M. (2017, January 06). 4 historic California storms that caused serious destruction. Retrieved November 27, 2020, from https://sf.curbed.com/2017/1/6/14192942/california-storm-atmospheric-river-d amage

Catto, J. L. (2016), Extratropical cyclone classification and its use in climate studies, Rev. Geophys., 54, 486-520, doi:10.1002/2016RGoo0519.

Gelaro, R., McCarty, W., Suárez, M.J., Todling, R., Molod, A., Takacs, L., Randles, C.A., Darmenov, A., Bosilovich, M.G., Reichle, R. and Wargan, K., 2017. The modern-era retrospective analysis for research and applications, version 2 (MERRA-2). Journal of Climate, 30(14), pp.5419-5454.

Guan, B., and D. E. Waliser (2015), Detection of atmospheric rivers: Evaluation and application of an algorithm for global studies, J. Geophys. Res. Atmos., 120, 12,514-12,535, doi:10.1002/2015JDo24257.

Hawcroft, M. K., Shaffrey, L. C., Hodges, K. I., and Dacre, H. F. (2012), How much Northern Hemisphere precipitation is associated with extratropical cyclones?, Geophys. Res. Lett., 39, L24809, doi:10.1029/2012GL053866.

Martin, A. C., Ralph, F. M., Wilson, A., DeHaan, L., \& Kawzenuk, B. (2019). Rapid Cyclogenesis from a Mesoscale Frontal Wave on an Atmospheric River: Impacts on Forecast Skill and Predictability during Atmospheric River Landfall. Journal of Hydrometeorology, 20(9), 1779-1794. https://doi-org.proxy.lib.pdx.edu/10.1175/JHM-D-18-0239.1 
Neiman, P.J., Moore, B.J., White, A.B., Wick, G.A., Aikins, J., Jackson, D.L., Spackman, J.R. and Ralph, F.M., 2016. An airborne and ground-based study of a long-lived and intense atmospheric river with mesoscale frontal waves impacting California during CalWater-2014. Monthly weather review, 144(3), pp.1115-1144.

Neiman, P. J., F. M. Ralph, G. A. Wick, J. D. Lundquist, and M. D. Dettinger, 2008: Meteorological Characteristics and Overland Precipitation Impacts of Atmospheric Rivers Affecting the West Coast of North America Based on Eight Years of SSM/I Satellite Observations. J. Hydrometeor., 9, 22-47, https://doi.org/10.1175/2007JHM855.1.

Ralph, F. M., Rutz, J. J., Cordeira, J. M., Dettinger, M., Anderson, M., Reynolds, D., Schick, L. J., \& Smallcomb, C. (2019). A Scale to Characterize the Strength and Impacts of Atmospheric Rivers, Bulletin of the American Meteorological Society, 100(2), 269-289. Retrieved May 20, 2021, from https://journals.ametsoc.org/view/journals/bams/100/2/bams-d-18-0023.1.xml

Ralph, F.M., Neiman, P.J., Kiladis, G.N., Weickmann, K. and Reynolds, D.W., 2010. A multi-scale observational case study of a Pacific atmospheric river exhibiting tropical-extratropical connections and a mesoscale frontal wave. Monthly Weather Review.

Rhoades, A. M., Jones, A. D., Srivastava, A., Huang, H., O'Brien, T. A., Patricola, C. M., et al.. (2020). The shifting scales of western U.S. landfalling atmospheric rivers under climate change. Geophysical Research Letters, 47, e2020GL089096. https://doi-org.proxy.lib.pdx.edu/10.1029/2020GL089096

Rutledge, S. A., and P. Hobbs, 1983: The Mesoscale and Microscale Structure and Organization of Clouds and Precipitation in Midlatitude Cyclones. VIII: A Model for the "Seeder-Feeder" Process in Warm-Frontal Rainbands. J. Atmos. Sci., 40, 1185-1206, https://doi.org/10.1175/1520-0469(1983)040<1185:TMAMSA>2.0.CO;2.

Rutledge, S. A., and P. V. Hobbs, 1984: The Mesoscale and Microscale Structure and Organization of Clouds and Precipitation in Midlatitude Cyclones. XII: A Diagnostic Modeling Study of Precipitation Development in Narrow Cold-Frontal Rainbands. J. Atmos. Sci., 41, 2949-2972, https://doi.org/10.1175/1520-0469(1984)041<2949:TMAMSA>2.0.CO;2. 
Schemm, S., \& Sprenger, M. (2015). Frontal-wave cyclogenesis in the North Atlantic -a climatological characterisation. Quarterly Journal of the Royal Meteorological Society, 141(693), 2989-3005.

https://doi-org.proxy.lib.pdx.edu/10.1002/qj.2584

Schultz, D. M., and Coauthors, Extratropical Cyclones: A Century of Research on Meteorology's Centerpiece. Meteor. Monogr., 2018; 59 16.1-16.56. doi: https://doi.org/10.1175/AMSMONOGRAPHS-D-18-0015.1.

YANJUAN GUO, TOSHIAKI SHINODA, BIN GUAN, WALISER, D. E., \& CHANG, E. K. M. (2020). Statistical Relationship between Atmospheric Rivers and Extratropical Cyclones and Anticyclones. Journal of Climate, 33(18), 7817-7834. https://doi-org.proxy.lib.pdx.edu/10.1175/JCLI-D-19-0126.1

Wernli, H., and C. Schwierz, 2006: Surface Cyclones in the ERA-40 Dataset (1958-2001). Part I: Novel Identification Method and Global Climatology. J. Atmos. Sci., 63, 2486-2507, https://doi.org/10.1175/JAS3766.1.

Zhu, Y., and R. E. Newell (1998), A proposed algorithm for moisture fluxes from atmospheric rivers, Mon. Weather Rev., 126, 725-735, doi:10.1175/1520-0493(1998)126<0725:APAFMF>2.0.CO;2.

\section{Acknowledgements:}

- U.S. Army Corps of Engineers

- Portland State University LSAMP

- Portland State University Climate Lab

- My advisor, Dr. Andrew Martin 